\title{
Enhancing flora balance in the gastrointestinal tract of mice by lactic acid bacteria from Chinese sourdough and enzyme activities indicative of metabolism of protein, fat, and carbohydrate by the flora
}

\author{
Dong Yang, ${ }^{*}$ Xiaomin Yu, ${ }^{*}$ Yaoping Wu, ${ }^{*}$ Xingxing Chen, ${ }^{*}$ Hua Wei, ${ }^{*}$ Nagendra $P$. Shah,,${ }^{1}$ and Feng $X{ }^{* 1}$ \\ *State Key Laboratory of Food Science and Technology, Nanchang University, Nanchang, Jiangxi, 330047, P. R. China \\ †Food and Nutritional Science, School of Biological Science, The University of Hong Kong, Pokfulam Road, Hong Kong 999077, China
}

\section{ABSTRACT}

In this study, we investigated the effect of administration of 5 strains of lactic acid bacteria (LAB) isolated from traditional Chinese sourdough on the flora balance of gastrointestinal tract of mice. We specifically measured Enterococcus, Enterobacter, Bacteroides, and Lactobacillus by plate count and real-time PCR methods, and $\alpha$-glucosidase, lactate dehydrogenase, esterase, and aminopeptidase activities as indicative of metabolism of sugar, fat, and protein from LAB isolated from feces of mice in vitro. The results showed that administration of Lactobacillus acidophilus LAC0201 and Lactobacillus fermentum LFE0302 lowered the uric acid index of serum. Lactobacillus acidophilus LAC0201, L. fermentum LFE0302, as well as Lactobacillus curvatus LCU0401 administration resulted in a reduction in the opportunistic pathogens (i.e., Enterococcus and Enterobacter), meanwhile, administration of $L$. fermentum LFE0302 and Lactobacillus sp. ULA0104 resulted in an increase in the counts of Lactobacillus. Lactobacillus fermentum LFE0302 administration increased starch digestion of intestinal flora after 4 wk of feeding and also resulted in increased $\alpha$-glucosidase activity in the intestinal flora after 3 wk of feeding. We found a similar trend in esterase activity after administration of L. acidophilus LAC0201 for 3 wk. Hence, our study suggested that LAB from Chinese sourdough might be used as potential probiotics to strengthen the flora balance in gastrointestinal tract and positively change the metabolism of nutrients through bacterial enzyme activities.

Key words: lactic acid bacteria, sourdough, mice gut flora, bacterial enzyme activity

Received May 16, 2016.

Accepted June 17, 2016

${ }^{1}$ Corresponding authors: npshah@hku.hk and ziwu211@126.com

\section{INTRODUCTION}

Sourdough is a mixture of flour and water fermented with heterofermentative lactic acid bacteria (LAB), which produce lactic acid and acetic acids and result in a sour taste (De Vuyst and Neysens, 2005). Sourdough has been employed as an inoculum in making Chinese steamed bread, a staple food in China for more than 2,000 yr (Liu et al., 2016), and also widely used in Western countries as a starter for bread-making (Bessmeltseva et al., 2014). The positive effect of sourdough utilization is due to its microbiota, which is a unique ecosystem predominantly comprising LAB and yeast (Gobbetti, 1998). Additionally, isolating probiotic organisms from traditional fermented foods has been another important source of isolating probiotic organisms in many countries (ben Omar and Ampe, 2000; Tamime, 2002; Chen et al., 2012). These LAB have attracted much attention due to their role in health promotion.

Recently, LAB were reported to give a positive influence on the composition of the gut microbiota of mice and human (Xie et al., 2016). Lactobacillus plantarum NCU116 attenuates cyclophosphamide-induced intestinal mucosal injury, metabolism, and intestinal microbiota disorders in mice. Lactobacillus fermentum CECT5716 prevents and alleviates intestinal damage induced in mice (Mañé et al., 2009) and reduces the incidence of upper respiratory and gastrointestinal tract infections in 6-mo-old infant humans (Arroyo et al., 2010). Numerous studies have demonstrated that modifying the gut microbiota with Lactobacillus strains has beneficial effects, such as improving glucose homeostasis and reducing inflammation and hepatic steatosis (Delzenne et al., 2011). Probiotics may modify the bile acid profile in the gut. Sayin et al. (2013) reported that colonization by a transformed bacterium that increased bile salt hydrolase activity influenced host metabolic processes. Enzymes produced by bacteria also participate in the digestion of fat and simple sugars in the small intestine (Drissi et al., 2016). Nearly 10,000 bacterial enzymes involved in the digestion of sugars have 
been identified, allowing bacteria to ensure constant supply of carbon source (El Kaoutari et al., 2013).

To date, scientists have mainly focused on the changes in the structure of gut flora after administration of LAB, but only a few studies have reported changes resulting from sugar, fat, and protein metabolism in the host. Most of the studies pertaining to sourdough have focused on either flavor substance of sourdough during processing or sourdough microbes. However, only a few studies reported nutrient metabolism by LAB and their enzyme activities of the host gut microbiota as influenced by the LAB from sourdoughs.

Therefore, in the current study, we investigated the effect of administration of 5 strains of LAB isolated from sourdough on the flora balance of mice. We specifically measured Enterococcus, Enterobacter, Bacteroides, and Lactobacillus by plate count and real-time PCR methods, as well as $\alpha$-glucosidase, lactate dehydrogenase, esterase, and aminopeptidase activities as indicative of metabolism of sugar, fat, and protein by fecal flora of mice in vitro.

\section{MATERIALS AND METHODS}

\section{Cultivation and Preparation of LAB}

Five strains-Lactobacillus helveticus LHE0103, Lactobacillus acidophilus LAC0201, Lactobacillus sp. ULA0104, Lactobacillus fermentum LFE0302, and Lactobacillus curvatus LCU0401-were isolated from sourdough purchased from markets in Shangdong province, China. Before conducting experiments, the LAB were cultured in de Man, Rogosa, and Sharpe broth (MRS; Beijing Solarbio Science and Technology Co. Ltd., Beijing, China) at $37^{\circ} \mathrm{C}$ for $24 \mathrm{~h}$ in an anaerobic incubator (Shanghai Xinnuo Instrument Equipment Co. Ltd., Shanghai, China). The strains were cultured to exponential phase and then centrifuged at $1,740 \times$ $g$ at $4^{\circ} \mathrm{C}$ for $10 \mathrm{~min}$. Then, the cells were washed twice with sterile physiological saline and resuspended in sterile physiological saline to adjust the cell concentration to $10^{9} \mathrm{cfu} / \mathrm{mL}$.

\section{Animal and Animal Experiments}

The protocol for the animal experiment was approved by Nanchang University Animal Ethical Committee and all the ethical requirements to conduct the experiment were met (approval number 0064257). Thirty-six adult (6-8 wk old) female healthy BALB/c mice (20-30 $\mathrm{g}$ each) were purchased from the experimental animal center of Nanchang University. The animals were kept in an animal facility at room temperature $\left(20^{\circ} \mathrm{C}\right)$ and $50 \%$ relative humidity with a 12 -h light/dark cycle. Af- ter the acclimatization to the experimental facility for $1 \mathrm{wk}$ (d -7 to 0 in Figure 1), the mice were randomly divided into 6 groups $(\mathrm{n}=6)$. The control group was administrated by oral gavage with $200 \mu \mathrm{L}$ of sterile physiological saline once every $2 \mathrm{~d}$ for $28 \mathrm{~d}$. Experimental groups were administrated via gastric gavage once every $2 \mathrm{~d}$ with $200 \mu \mathrm{L}$ of bacterial suspension for $28 \mathrm{~d}$. The collection of fecal samples was scheduled at 5 time points: $0,7,14,21$, and $28 \mathrm{~d}$.

\section{Serum Biochemical Indices}

Mice were anaesthetized by ethyl ether and the blood was collected from the orbital sinus by quickly removing the eyeball, and approximately $1 \mathrm{~mL}$ of blood was centrifuged (at $1,000 \times g$ at $4^{\circ} \mathrm{C}$ for $10 \mathrm{~min}$ ) to obtain at least $0.25 \mathrm{~mL}$ of blood plasma for serum biochemistry. The residual blood from each mouse was taken from the eye socket. The blood serum was examined at the First Affiliated Hospital of Nanchang University, Nanchang, China. Each sample was tested 3 times. The examined indicators included alanine aminotransferase (ALT), aspartate aminotransferase (AST), total bilirubin (TBIL), and direct bilirubin (DBIL), which were used to evaluate liver function. Creatinine (CREA), BUN, and uric acid (UA) were used to evaluate renal function. Blood glucose, total cholesterol, and triglyceride we used to evaluate blood sugar, blood fat, and cholesterol levels.

\section{Viable Counts in Mice Feces Using Plate Count Method}

Viable counts of Enterococcus, Enterobacter, Bacteroides, and Lactobacillus in mice feces were enumerated using plate count method using selective medium. The SBM medium (Slanetz and Bartley medium, Oxoid, Basingstoke, UK) was used for Enterococcus, MAC medium (MacConkey, Oxoid) was used for Enterobacter, modified GAM medium (Gifu anaerobic medium, Qingdao Hope Bio-technology Co. Ltd., Qingdao, China) was used for Bacteroides, and MRS medium was used for Lactobacillus. Enterococcus and Enterobacter were incubated under aerobic conditions $\left(37^{\circ} \mathrm{C}, 24 \mathrm{~h}\right)$. Bacteroides and Lactobacillus were incubated under anaerobic conditions $\left(37^{\circ} \mathrm{C}, 48 \mathrm{~h}\right)$.

\section{Viable Counts in Mice Feces Using Real-Time PCR method}

Total genomic DNA was extracted from the homogenized fecal samples according to the bead-beating modified method (Simões et al., 2013). An amount of Escherichia coli JM109, which harbors pPIC9 vectors, 
Table 1. Primers used in real-time PCR

\begin{tabular}{lll}
\hline Target genus & Forward primer $\left(5^{\prime}-3^{\prime}\right)$ & Reverse primer $\left(5^{\prime}-3^{\prime}\right)$ \\
\hline Enterococcus & CCCTTATTGTTAGTTGCCATCAT & ACTCGTTGTACTTCCCATTGT \\
Enterobacter & CATGACGTTACCCGCAGAAGAAG & CTCTACGAGACTCAAGCTTGC \\
Bacteroides & GGTGTCGGCTTAAGTGCCAT & CGGA(C/T)GTAAGGGCCGTGC \\
Lactobacillus & CACCGCTACACATGGAG & AGCAGTAGGGAATCTTCCA \\
\hline
\end{tabular}

was added to each fecal sample before DNA extraction to determine the quantities of DNA as an internal standard; this was generated by analysis of the DNA banding profiles produced by real-time PCR (Park and Crowley, 2005). Briefly, samples were suspended in $600 \mu \mathrm{L}$ of lysis buffer (4\% SDS, $50 \mathrm{~m} M$ EDTA, 50 $\mathrm{m} M$ Tris-HCl, $500 \mathrm{~m} M \mathrm{NaCl}, \mathrm{pH} 8.0)$ and $400 \mu \mathrm{L}$ of phenol-chloroform-isoamylalcohol $(25: 24: 1)$ in a screwcapped tube containing $0.4 \mathrm{~g}$ of sterile zirconium beads (diameter $=0.1 \mathrm{~mm}$ ). The tubes were then vortexed for $5 \mathrm{~min}$ in a turbine mixer following extraction using phenol-chloroform. After extraction, the total DNA was precipitated with ethanol and suspended in $50 \mu \mathrm{L}$ of Tris-EDTA (TE) buffer (Tris-HCl buffer, $\mathrm{pH}$ 8.0, containing $1.0 \mathrm{~m} M$ EDTA) and stored at $-20^{\circ} \mathrm{C}$ before use.

Real-time PCR was performed using a commercial kit (Real Master-Mix, SYBR Green, Tiangen Biotech, Tiangen, China). Amplification and detection were carried out in 96-well plates with a 7900 HT Fast real-time PCR System (Applied Biosystems, Foster City, CA).
The PCR was carried out in a final volume of $20 \mu \mathrm{L}$. Thermal cycler conditions were $95^{\circ} \mathrm{C}$ for $3 \mathrm{~min}$, followed by 40 cycles at $95^{\circ} \mathrm{C}$ for $5 \mathrm{~s}$, and then $60^{\circ} \mathrm{C}$ for $30 \mathrm{~s}$. Each test was performed in duplicate. Relative DNA levels were determined by comparative critical threshold real-time PCR (in a separate tube), as described by Applied Biosystems User Bulletin no. 2 (P/N 4303859). Primers used in real-time PCR are listed in Table 1.

\section{Bile Tolerance Assay}

Bile tolerance of anaerobic bacteria from mice gut flora was investigated. The MRS broth and nutrient broth were adjusted with bile salt (Beijing Solarbio Science and Technology Co. Ltd.) to a concentration of $0.35 \%$. The MRS broth was adjusted to a $\mathrm{pH}$ of 6.2 and nutrient broth was adjusted to a $\mathrm{pH}$ of 7.0. Each medium, containing $1 \%$ fecal suspension, was cultured at $37^{\circ} \mathrm{C}$ for $12 \mathrm{~h}$ in the 96 -well plate. The growth of intestinal flora was monitored by measuring absorbance at $600 \mathrm{~nm}$. Each assay was performed in triplicate.

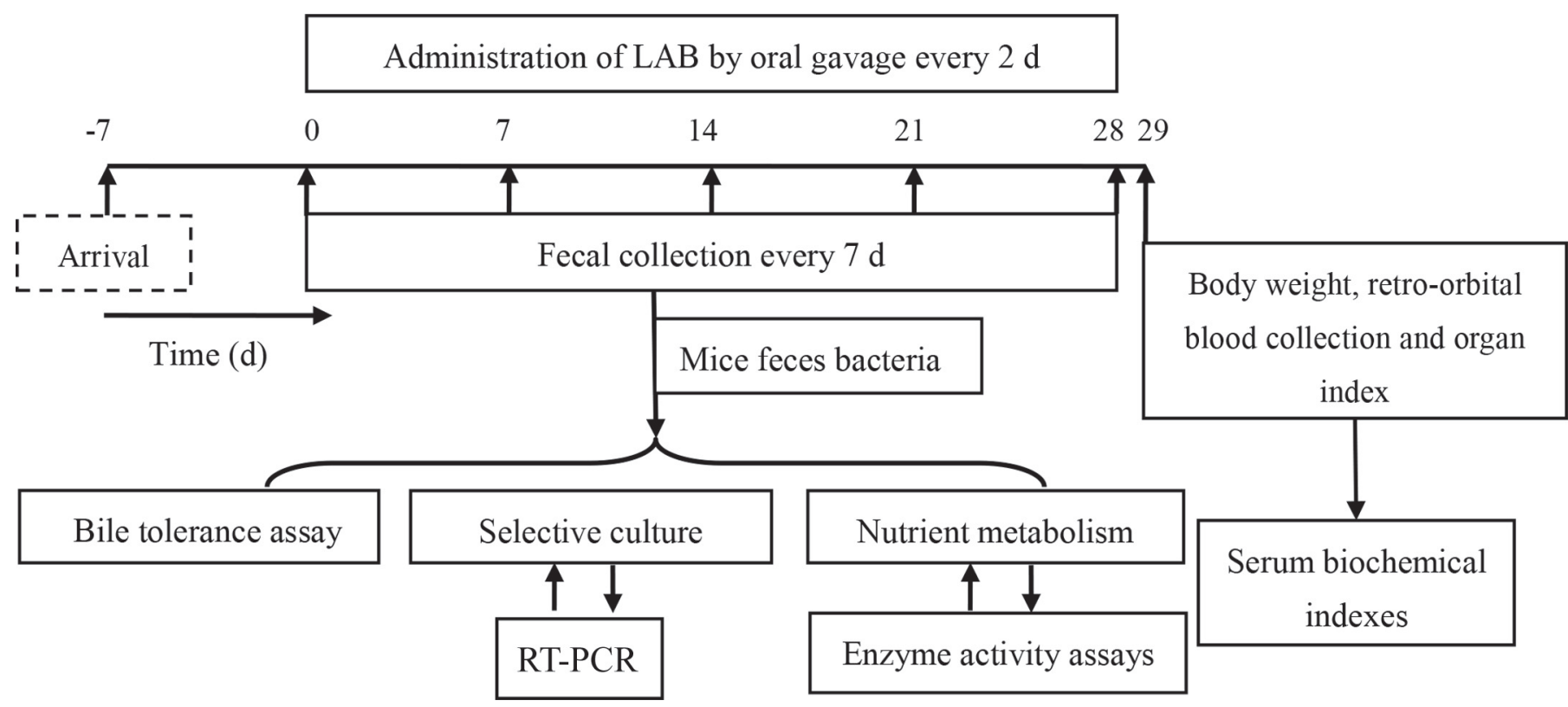

Figure 1. Timeline of the animal experiment. Mice were acclimatized for 1 wk followed by administration of $200 \mu \mathrm{L}$ of lactic acid bacteria (LAB) suspension by oral gavage every other day for $28 \mathrm{~d}$. Feces collections were scheduled at 5 time points: $0,7,14,21$, and 28 d. RT-PCR $=$ real-time PCR. 


\section{Nutrient Metabolism}

The amylose metabolic rate assay was performed as previously described with some modifications (Vilaplana et al., 2012). Briefly, $1 \%$ feces suspension and $5 \%$ amylose were added to MRS broth $(\mathrm{pH} 6.2)$ and cultured anaerobically at $37^{\circ} \mathrm{C}$ for $24 \mathrm{~h}$. Then, $1 \%$ feces suspension and $5 \%$ amylose were added to nutrient broth $(\mathrm{pH}$ 7.0) and incubated under aerobic conditions at $37^{\circ} \mathrm{C}$ for $24 \mathrm{~h}$. One milliliter of the culture was dispersed in $1 \mathrm{~mL}$ of ethanol, and then $5 \mathrm{~mL}$ of $\mathrm{NaOH}$ solution (1 $M$ ) was added with swirling to improve the dispersion. The mixture was heated in the boiling water bath for 10 min after the amylose was completely gelatinized, and then distilled water was added to a final volume of $50 \mathrm{~mL}$. Five-milliliter samples were taken into 50$\mathrm{mL}$ volumetric flasks and neutralized with acetic acid solution $(1 \mathrm{M})$. Then, $1 \mathrm{~mL}$ of fresh iodine solution $(0.2$ $\mathrm{g}$ of $\mathrm{I}_{2}+2 \mathrm{~g}$ of $\mathrm{KI}+250 \mathrm{~mL}$ of distilled water) and distilled water were added to $50 \mathrm{~mL}$ and the sample was kept at $30^{\circ} \mathrm{C}$ for $20 \mathrm{~min}$. The optical density (OD) of duplicate subsamples was read at $620 \mathrm{~nm}$. A control was run without intestinal flora under the same set of conditions. Amylose metabolic rate was calculated by using the following equation:

\section{Amylose metabolic rate $(\%)=$}

(Abs of control - Abs of culture)/Abs of control,

where Abs = absorbance.

The oil metabolism assay was carried out as previously described with some modifications (Hassanshahian et al., 2014). Briefly, $2 \%$ of feces suspension and $1 \%$ soybean oil were added to MRS broth ( $\mathrm{pH} 6.2)$ and cultured anaerobically at $37^{\circ} \mathrm{C}$ for $24 \mathrm{~h}$. Then, $1 \%$ feces suspension and $2 \%$ soybean oil were added to nutrient broth $(\mathrm{pH}$ 7.0) and incubated under aerobic conditions at $37^{\circ} \mathrm{C}$ for $24 \mathrm{~h}$. After incubation, the residual oil of the medium was dissolved in dichloromethane. The OD of the oil extract against the blank was read at $420 \mathrm{~nm}$. A control was run without intestinal flora under the same set of conditions. Oil metabolic rate was calculated by using the following equation:

$$
\text { Oil metabolic rate }(\%)=
$$

(Abs of control - Abs of culture)/Abs of control.

The ovalbumin metabolism assay was determined as follow. In brief, $1 \%$ feces suspension and $1 \%$ ovalbumin were added to MRS broth ( $\mathrm{pH}$ 6.2) and cultured anaerobically at $37^{\circ} \mathrm{C}$ for $24 \mathrm{~h}$. Then, $2 \%$ feces suspension and $1 \%$ ovalbumin were added to nutrient broth $(\mathrm{pH}$
7.0) and incubated under aerobic conditions at $37^{\circ} \mathrm{C}$ for $24 \mathrm{~h}$. Then, a 96-well ELISA plate was coated with $100 \mu \mathrm{L} /$ well of polyclonal antibody against ovalbumin and incubated at $4^{\circ} \mathrm{C}$ overnight. The overnight-coated ELISA plate was washed thrice with wash buffer solution and the wells were then blocked with $150 \mu \mathrm{L}$ of blocking solution for $1 \mathrm{~h}$ at $37^{\circ} \mathrm{C}$. Following incubation, the plate was washed 4 times and $100 \mu \mathrm{L}$ of the culture was transferred to duplicate wells and incubated at $37^{\circ} \mathrm{C}$ for $1 \mathrm{~h}$. Then the wash sequence was repeated and 100 $\mu \mathrm{L}$ of anti-bovine horseradish peroxidase-conjugated monoclonal antibody against ovalbumin was added and incubated at $37^{\circ} \mathrm{C}$ for $1 \mathrm{~h}$. At the end of the incubation, the wash sequence was repeated, and then $100 \mu \mathrm{L}$ of tetramethylbenzidine substrate was added to all wells, and kept in the dark at room temperature for $15 \mathrm{~min}$. The reaction was stopped by the addition to each well of $50 \mu \mathrm{L}$ of stop solution and the OD was measured at $450 \mathrm{~nm}$. A control was run without intestinal flora under the same set of conditions. Ovalbumin metabolic rate was calculated by using the following equation:

$$
\text { Ovalbumin metabolic rate }(\%)=
$$

(Abs of control - Abs of culture)/Abs of control.

\section{Enzyme Activities Assays}

For enzyme assays, $1 \%$ feces suspension was added to MRS broth (pH 6.2) and cultured anaerobically at $37^{\circ} \mathrm{C}$ for $24 \mathrm{~h}$, and $1 \%$ feces suspension was added to nutrient broth (pH 7.0) and incubated under aerobic conditions at $37^{\circ} \mathrm{C}$ for $24 \mathrm{~h}$. Fresh feces directly washed with sterile physiological saline was used as another group. The cells of 2 groups were washed once with sterile physiological saline and resuspended in physiological saline to adjust the cell concentration to $10^{8} \mathrm{cfu} / \mathrm{mL}$. Then, the cultures were broken for 10 min with an ultrasonic cell disruption system (Ningbo Scientz Biotechnology Co. Ltd., Ningbo, China). The insoluble fraction was discarded after centrifuging for $3 \mathrm{~min}$ at $10,010 \times \mathrm{g}$ at $4^{\circ} \mathrm{C}$.

The $\alpha$-glucosidase activity was performed using $p$-nitrophenyl- $\alpha$-D-glucopyranoside as the substrate as previously described, with some modifications (Scalabrini et al., 1998; Tsangalis et al., 2002). The mixture containing $100 \mu \mathrm{L}$ of crude enzyme solution and 900 $\mu \mathrm{L}$ of $p$-nitrophenyl- $\alpha$-D-glucopyranoside solution (1 $\mathrm{m} M$ ) was incubated for $25 \mathrm{~min}$ at $37^{\circ} \mathrm{C}$. The speed of nitrophenol release, which is directly proportional to the $\alpha$-glucosidases activity, was monitored continuously by measuring the increase in absorbance over $3 \mathrm{~min}$ at $410 \mathrm{~nm}$. 
Lactate dehydrogenase (LDH) activity was assayed as previously described, with some modifications (Ishihara et al., 1999). The pyruvate solution $(1 \mathrm{mM})$ and the NADH solution $(0.3 \mathrm{mM})$ were preheated at $25^{\circ} \mathrm{C}$ for $20 \mathrm{~min}$ in a water bath. The LDH activity was assayed in a mixture containing $700 \mu \mathrm{L}$ of pyruvate solution, $20 \mu \mathrm{L}$ of the NADH solution, and $50 \mu \mathrm{L}$ of the crude enzyme solution. The LDH activity was evaluated by measuring the decrease in absorbance over 3 min at $340 \mathrm{~nm}$.

Esterase activity was measured as previously described by using fluorescein diacetate as a substrate (Breeuwer et al., 1995). The esterase activity was assayed in the mixture containing $50 \mu \mathrm{L}$ of crude enzyme solution and $300 \mu \mathrm{L}$ of fluorescein diacetate solution (4 $\mu M)$. The esterase activity was determined by measuring the increase in fluorescence intensity over $1 \mathrm{~min}$ at $520 \mathrm{~nm}$ with excitation at $466 \mathrm{~nm}$.

Aminopeptidase activity was measured as previously described using L-Leu- $p$-nitroanilide as a substrate with some modifications (Gaur et al., 2010). Aminopeptidase activity was assayed in the mixture containing 200 $\mu \mathrm{L}$ of crude enzyme solution and $300 \mu \mathrm{L}$ of L-Leu- $p$ nitroanilide hydrochloride $(10 \mathrm{mM})$. The mixture was incubated at $37^{\circ} \mathrm{C}$ for $15 \mathrm{~min}$. The aminopeptidase activity was monitored by measuring the increase in absorbance at $405 \mathrm{~nm}$. Each assay was measured in triplicate.

\section{Statistical Analysis}

The tests for all the experiments were carried out in triplicate. All data were expressed as means \pm standard deviation of the 3 parallel tests. We used SPSS version 19.0 software for statistical analyses (IBM Corp., Armonk, NY) by means of independent one-way ANOVA tests. The figures were depicted by using Graph-Pad Prism 5.0 software (GraphPad Software Inc., La Jolla, CA).

\section{RESULTS}

\section{Isolation and Selection of $L A B$}

One hundred isolates were obtained from sourdough samples of Shandong province, China, and their gene sequences were determined by $16 \mathrm{~S}$ rDNA gene sequencing. Thirteen were categorized into LAB, belonging to 8 species of bacteria (i.e., Lactobacillus paracasei, Lactobacillus plantarum, Lactobacillus sp., Pediococcus pentosaceus, Lactobacillus curvatus, Lactobacillus fermentum, Lactobacillus helveticus, and Lactobacillus acidophilus). Lactobacillus helveticus LHE0103, Lactobacillus acidophilus LAC0201, Lactobacillus sp. ULA0104,
Lactobacillus fermentum LFE0302, and Lactobacillus curvatus LCU0401 were selected based on fast acidification and high yields of free AA (data not shown). All 5 strains were further evaluated for their effect on the constituent of intestinal flora of mice.

\section{Physiological and Biochemical Indexes of Serum}

Physiological and biochemical indexes of serum from animals gavaged with LAB were evaluated. As shown in Figure 2A to D, we found a slight but nonsignificant difference in the level of ALT, AST, TBIL, and DBIL when compared with the control group $(P>0.05)$, indicating that the 5 strains had no effect on liver cell integrity or liver function. For indexes of BUN, CREA, and UA, reflecting the renal lesion, only UA presented a significant change after the administration of $L$. acidophilus LAC0201 and L. fermentum LFE0302. For the index of glucose, total cholesterol, and triglyceride, which reflected glucose and lipid metabolism, we noted a nonsignificant change between test and control. Thus, all 5 LAB strains were safe for use as potential probiotics.

\section{Effect of $L A B$ on the Intestinal Flora Constituent of Mice}

We further evaluated effects on intestinal flora by both culture-dependent and culture-independent methods; namely, plate count and real-time PCR methods. Results of viable counts of Enterococcus, Enterobacter, Bacteroides, and Lactobacillus are summarized in Table 2. In general, we found a nonsignificant change in the flora (i.e., Enterococcus, Enterobacter, Bacteroides, and Lactobacillus) after 1 wk in all test groups, and only some of them presented a significant change after 2 wk of feeding. Both L. acidophilus LAC0201 and L. curvatus LCU0401 resulted in a significant reduction in cell counts after 2 to $4 \mathrm{wk}$ of Enterococcus and Bacteroides. Similarly, L. fermentum LFE0302, L. curvatus LCU0401, and L. helveticus LHE0103 significantly reduced the counts after 3 to 4 wk of Enterobacter and Bacteroides, whereas both Lactobacillus sp. ULA0104 and L. fermentum LFE0302 significantly increased the counts of Lactobacillus after 3 to 4 wk.

Results of real-time PCR (Figure 3) demonstrated that L. helveticus LHE0103 administration reduced the population of Bacteroides by 0.4569 -fold after $4 \mathrm{wk}$ and increased the population of Lactobacillus by a maximum of 2.247-fold in 3 wk. Lactobacillus acidophilus LAC0201 administration reduced Enterococcus by a maximum of 0.1022-fold in $3 \mathrm{wk}$ and reduced Bacteroides by 0.5414 fold after 4 wk. Lactobacillus sp. ULA0104 administration increased Lactobacillus by 4.880 -fold after 4 

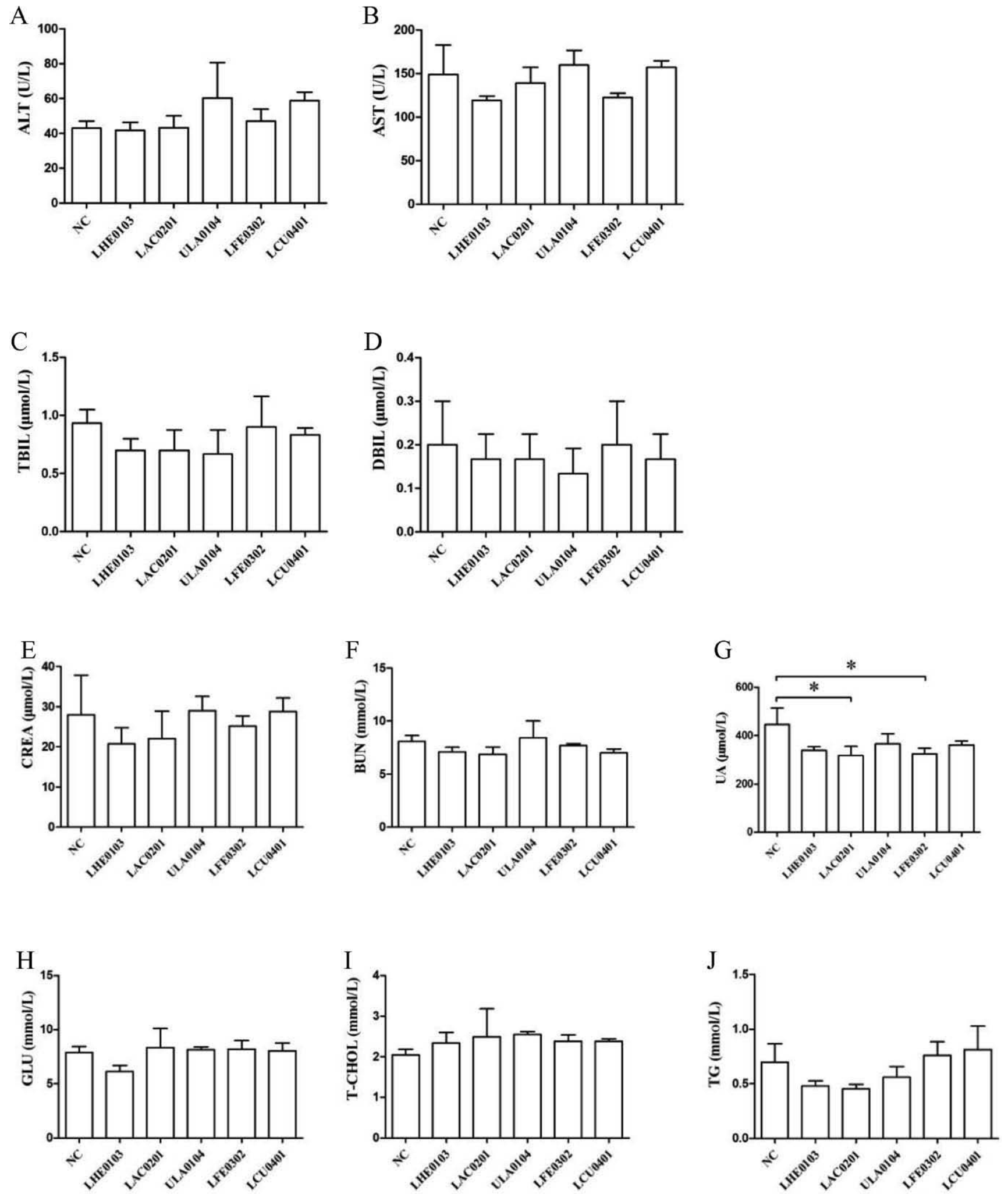

Figure 2. Serum biochemical analysis from animals gavaged with the bacteria isolated from sourdough (LHE103 = Lactobacillus helveticus LHE0103; LAC0201 = Lactobacillus acidophilus LAC0201; ULA0104 = Lactobacillus sp. ULA0104; LFE0302 = Lactobacillus fermentum LFE0302; LCU0401 = Lactobacillus curvatus LCU0401) and control (NC). Results represent the mean and SD of alanine aminotransferase (ALT; A), aspartate aminotransferase (AST; B), total bilirubin (TBIL; C), direct bilirubin, creatinine (CREA; D), urea nitrogen (BUN; F), uric acid (UA; G), blood glucose (GLU; H), total cholesterol (T-CHOL; I) and triglyceride (TG; J) n $=6$. ${ }^{*} P<0.05$ versus the control group. 
Table 2. The effect of the lactic acid bacteria isolated from sourdough on the intestinal flora of mice (means $\pm \mathrm{SD} ; \mathrm{n}=6$ )

\begin{tabular}{|c|c|c|c|c|c|c|c|}
\hline \multirow[b]{2}{*}{ Genus in flora } & \multirow[b]{2}{*}{$\begin{array}{l}\text { Time } \\
\text { (d) }\end{array}$} & \multicolumn{6}{|c|}{ Group (log cfu/g) } \\
\hline & & Control $^{1}$ & $\begin{array}{l}\text { Lactobacillus } \\
\text { helveticus } \\
\text { LHE0103 }\end{array}$ & $\begin{array}{l}\text { Lactobacillus } \\
\text { acidophilus } \\
\text { LAC0201 }\end{array}$ & $\begin{array}{l}\text { Lactobacillus } \\
\text { sp. ULA0104 }\end{array}$ & $\begin{array}{l}\text { Lactobacillus } \\
\text { fermentum } \\
\text { LFE0302 }\end{array}$ & $\begin{array}{c}\text { Lactobacillus } \\
\text { curvatus } \\
\text { LCU0401 }\end{array}$ \\
\hline \multirow[t]{3}{*}{ Enterococcus } & 0 & $8.17 \pm 1.03$ & $7.93 \pm 0.96$ & $7.61 \pm 0.59$ & $8.43 \pm 0.52$ & $8.03 \pm 0.49$ & $8.29 \pm 0.36$ \\
\hline & 7 & $7.80 \pm 1.01$ & $7.79 \pm 0.84$ & $7.64 \pm 1.33$ & $8.34 \pm 0.34$ & $7.68 \pm 0.29$ & $8.23 \pm 0.53$ \\
\hline & 14 & $8.07 \pm 0.11$ & $8.15 \pm 1.53$ & $6.98 \pm 0.21^{*}$ & $8.21 \pm 1.12$ & $7.84 \pm 0.38$ & $7.94 \pm 0.34^{*}$ \\
\hline \multirow[t]{5}{*}{ Enterobacter } & 0 & $8.23 \pm 1.17$ & $8.12 \pm 1.21$ & $7.83 \pm 0.95$ & $8.24 \pm 0.33$ & $8.52 \pm 0.59$ & $7.62 \pm 0.50$ \\
\hline & 7 & $8.31 \pm 0.13$ & $7.86 \pm 0.09$ & $7.91 \pm 0.84$ & $7.96 \pm 0.27$ & $8.44 \pm 1.33$ & $7.55 \pm 0.31$ \\
\hline & 14 & $8.28 \pm 0.11$ & $8.16 \pm 1.21$ & $8.03 \pm 0.95$ & $8.16 \pm 0.33$ & $8.78 \pm 0.59$ & $7.62 \pm 1.14$ \\
\hline & 21 & $8.07 \pm 1.23$ & $7.72 \pm 0.39$ & $8.21 \pm 0.53$ & $8.23 \pm 1.53$ & $7.56 \pm 0.4^{*}$ & $6.70 \pm 0.15^{*}$ \\
\hline & 28 & $8.18 \pm 0.71$ & $7.74 \pm 0.31$ & $7.97 \pm 0.34$ & $7.84 \pm 1.48$ & $7.27 \pm 0.13^{*}$ & $7.03 \pm 0.91^{*}$ \\
\hline \multirow[t]{2}{*}{ Bacteroides } & 0 & $8.86 \pm 0.35$ & $8.03 \pm 0.83$ & $8.87 \pm 0.34$ & $8.03 \pm 0.27$ & $8.46 \pm 0.32$ & $8.78 \pm 0.28$ \\
\hline & 7 & $8.74 \pm 0.33$ & $8.32 \pm 0.67$ & $8.63 \pm 0.23$ & $8.45 \pm 0.62$ & $8.13 \pm 0.55$ & $8.69 \pm 0.90$ \\
\hline \multirow{3}{*}{ Lactobacillus } & 14 & $8.23 \pm 0.11$ & $8.53 \pm 0.83$ & $8.57 \pm 0.53$ & $8.16 \pm 0.83$ & $8.32 \pm 0.53$ & $8.25 \pm 0.04$ \\
\hline & 21 & $8.27 \pm 0.51$ & $8.75 \pm 0.35$ & $8.21 \pm 0.45$ & $9.01 \pm 0.75^{*}$ & $9.32 \pm 0.83^{*}$ & $8.31 \pm 0.53$ \\
\hline & 28 & $8.45 \pm 0.51$ & $8.37 \pm 0.35$ & $7.98 \pm 0.45$ & $9.14 \pm 0.75^{*}$ & $9.16 \pm 0.83^{*}$ & $8.45 \pm 0.53$ \\
\hline
\end{tabular}

${ }^{1}$ The control group was administered $200 \mu \mathrm{L}$ of sterile physiological saline by oral gavageonce every $2 \mathrm{~d}$ for $28 \mathrm{~d}$.

${ }^{*} P<0.05$ and ${ }^{* *} P<0.01$ versus the start time $(0 \mathrm{~d})$ of gavage.

wk. Lactobacillus fermentum LFE0302 administration reduced Enterobacter by 0.3426 -fold after $4 \mathrm{wk}$ and increased Lactobacillus by 6.476-fold after 4 wk. Lactobacillus curvatus LCU0401 administration reduced Enterococcus, Enterobacter, and Bacteroides by 0.1317-, 0.5321 -, and 0.5487 -fold after $4 \mathrm{wk}$, respectively.

The change in flora by LAB administration might affect the bile tolerance of intestinal flora of mice. Hence, we investigated the tolerance of anaerobic and aerobic bacteria by culturing in vitro in MRS and nutrient broth (NB). As shown in Figure 4A, a nonsignificant change occurred in bile tolerance of flora by gavage of 5 LAB strains in 2 wk. After 3 wk, only Lactobacillus sp. ULA0104 administration showed improvement of bile tolerance of anaerobic flora cultured in MRS, whereas administration of L. curvatus LCU0401 presented the same trend in 4 wk. Similar results were achieved for anaerobic cultivation, as shown in Figure 4B.

\section{Effect of LAB on the In Vitro Digestion Capacity}

The change in intestinal flora by LAB administration might also affect the digestion capacity of nutrients including sugar, protein, and oil. Therefore, a series of in vitro test for digestion of sugar, protein, and oil, and enzymatic activities of anaerobic and aerobic bacteria were performed. As shown in Figure 5, we noted a nonsignificant change in the metabolic capacity of intestinal flora, except for a significant increase in starch digestion in 4 wk by anaerobic bacteria in the test group of L. fermentum LFE0302.

Subsequently, the activities of $\alpha$-glucosidase, esterase, LDH, and aminopeptidase were tested. As shown in Figure 6 , we noted a significant increase in $\alpha$-glucosidase in the intestinal flora after administration of L. fermentum LFE0302 for 3 and 4 wk. Similarly, we observed a similar trend in esterase activity after administration of L. acidophilus LAC0201 for 3 and 4 wk.

\section{DISCUSSION}

In our study, $5 \mathrm{LAB}$ strains out of 100 isolates from sourdough of Shandong province, China, were evaluated for their use as a potential probiotic based on serum biochemical indices. The results showed no effect on liver function after the administration of $10^{8} \mathrm{cfu}$ of $\mathrm{LAB} /$ per day for $4 \mathrm{wk}$, reflected by the levels of ALT, AST, TBIL, and DBIL in mice serum. Also, we found no effect on glucose and lipid metabolism, partial renal parameters (i.e., BUN and CREA) as well as body and organ weight (data not shown). Many studies have shown the effect of Lactobacillus spp. on physiological and biochemical index of serum and BW based on animal models (Drissi et al., 2016). Interestingly, we found that administration of L. acidophilus LAC0201 and L. fermentum LFE0302 lowered the UA index of serum, indicating that 2 strains could be beneficial for patients with high UA and suffer from high blood pressure, hy- 
LHE0103

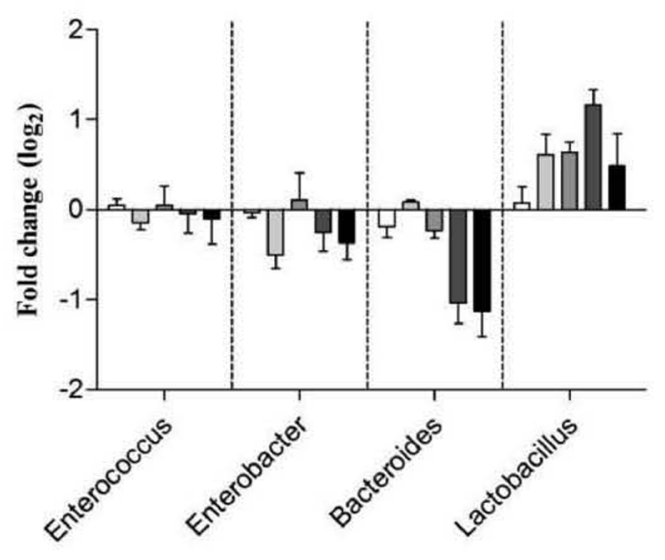

LAC0201

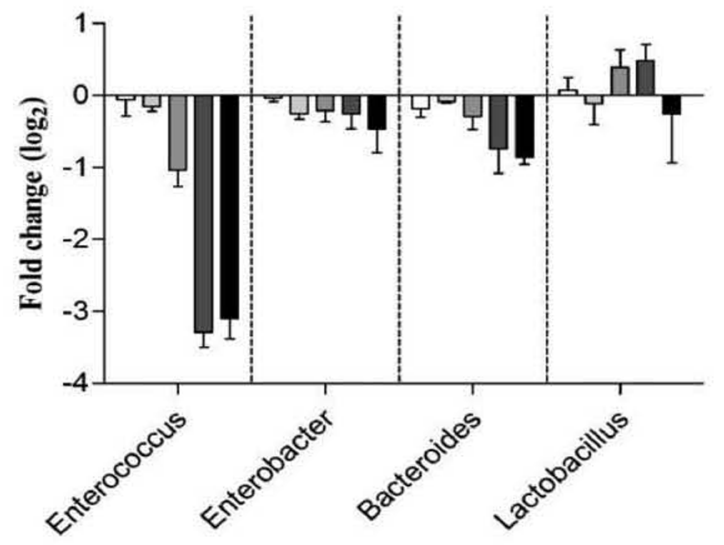

LFE0302

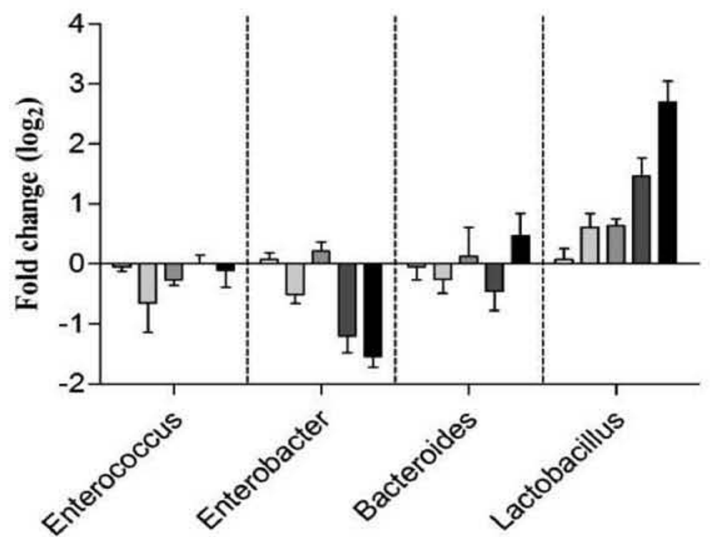

\section{ULA0104}

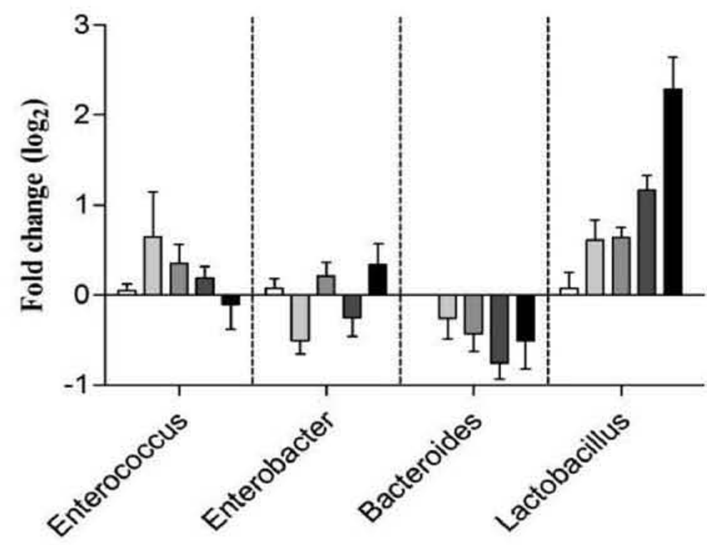

LCU0401

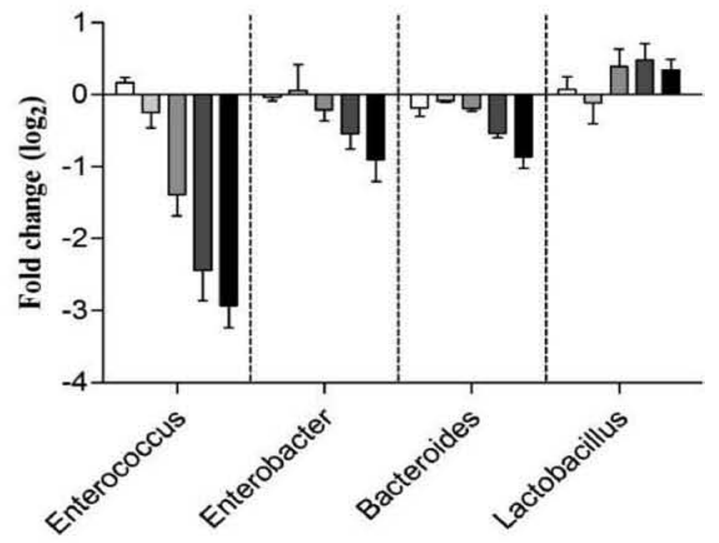

Figure 3. Primers specific to 4 special strains used for real-time PCR assays to quantify fold changes to represent relative abundance. The pPIC9 vector was used to normalize the input amounts of DNA, and the relative expression ratio was presented as a $\log _{2}$ value compared with the control group. LHE103 = Lactobacillus helveticus LHE0103; LAC0201 = Lactobacillus acidophilus LAC0201; ULA0104 = Lactobacillus sp. ULA0104; LFE0302 = Lactobacillus fermentum LFE0302; LCU0401 = Lactobacillus curvatus LCU0401. 

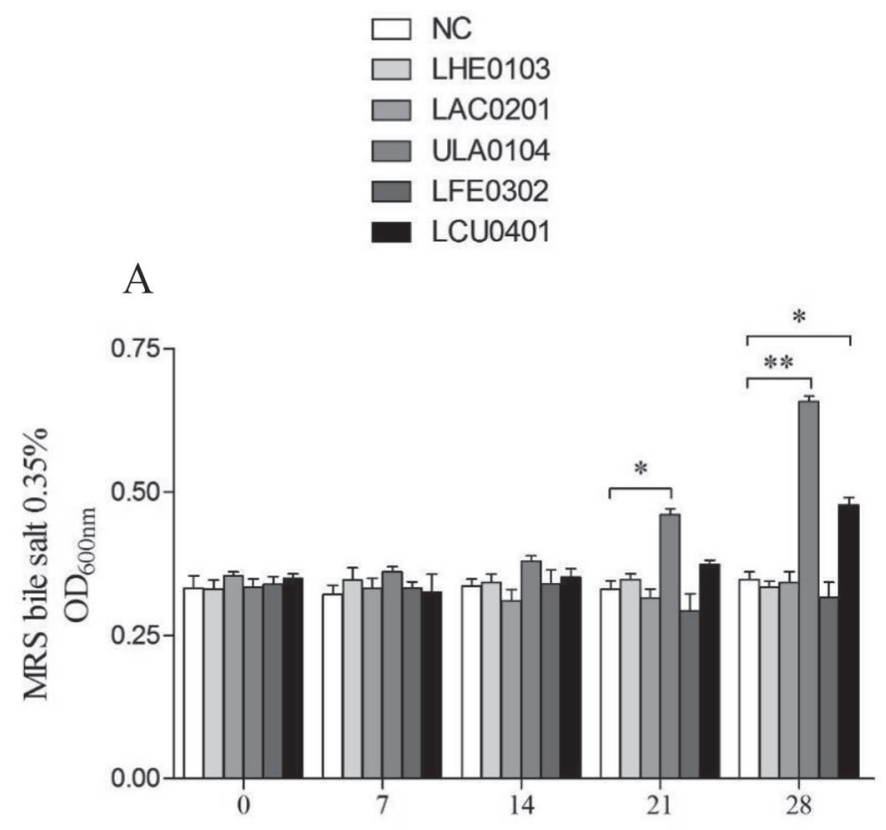

B

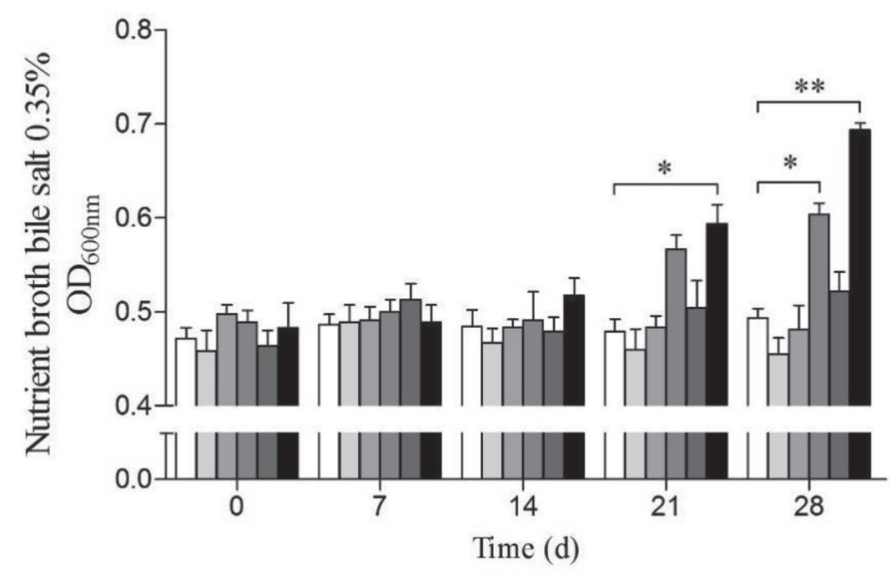

Figure 4. Growth of mice fecal bacteria at $0.35 \%$ concentration of bile salt in de Man, Rogosa, Sharpe (MRS) broth (A) and nutrient broth (B). ${ }^{*} P<0.05$ and ${ }^{* *} P<0.01$ versus the control group. $\mathrm{OD}_{600 \mathrm{~mm}}$ $=$ optical density at $600 \mathrm{~nm} ; \mathrm{NC}=$ sterile physiological saline; LHE103 $=$ Lactobacillus helveticus LHE0103; LAC0201 = Lactobacillus acidophilus LAC0201; ULA0104 = Lactobacillus sp. ULA0104; LFE0302 = Lactobacillus fermentum LFE0302; LCU0401 = Lactobacillus curvatus LCU0401.

perlipidemia, atherosclerosis, gout, and other diseases (Chen et al., 2015). Li et al. (2014) found LAB isolated from Chinese sauerkraut lowered UA in hyperuricemia rat group. Compared with results of Li et al. (2014), L. acidophilus LAC0201 and L. fermentum LFE0302 also have potential application as a probiotic for the prevention of hyperuricemia in a normal population.

The changes in serum biochemical indices might be relevant to the changes in the intestinal flora. Some studies have reported that LAB strains affect the functions of liver and kidney by changing the flora constituent (Koppe et al., 2015). Schnabl and Brenner (2014) summarized that Escherichia, Enterococcus, Enterobacter, and Lactobacillus were disproportionate between healthy people and patients with nonalcoholic fatty liver disease and nonalcoholic steatohepatitis. Ramezani and Raj (2014) concluded that lower intestinal microbial flora was shown to be altered in patients with chronic kidney disease, notably with decreases in both Lactobacillaceae and Prevotellaceae families as well as Enterobacter and Enterococcus species were approximately 100 times higher in hemodialysis patients.

In our study, by plate count and real-time PCR methods, we found that administration of 2 strains ( $L$. acidophilus LAC0201 and L. fermentum LFE0302) as well as L. curvatus LCU0401 resulted in a significant reduction in the opportunistic pathogens (i.e., Enterococcus and Enterobacter), whereas L. fermentum LFE0302 and Lactobacillus sp. ULA0104 resulted in a significant increase in counts of Lactobacillus. This indicated that L. acidophilus LAC0201, L. fermentum LFE0302, L. curvatus LCU0401, and Lactobacillus sp. ULA0104 might be able to modify intestinal microbiota toward a positive flora balance.

Alteration of microbiota composition appears to have a direct effect on the host metabolism. Our results showed a correlation between metabolism of sugar and enzymatic activities of anaerobic and aerobic bacteria. For instance, enhanced energy harvest is related to increased metabolism of starch, reflecting the $\alpha$-glucosidase activity. It was reported that fecal microbiota of obese people has an increased capacity to harvest energy (Tremaroli and Bäckhed, 2012). The body's metabolism is related not only to enzyme activity in the gut, but also to enzyme activity of gut microbiota (Wu et al., 2013). Therefore, we found that $L$. fermentum LFE0302 isolated from sourdough changed the structure of gut microbiota and subsequently changed the enzyme activities yielded by flora and thus affect substance metabolism in gastrointestinal tract of the host. In summary, LAB from Chinese sourdough appeared to be safe for use and L. fermentum LFE0302 might be regarded as a potential probiotic to strengthen the flora balance in gastrointestinal tract and positively change the substance metabolism through bacterial enzyme activity.

\section{CONCLUSIONS}

Lactobacillus fermentum LFE0302, originally isolated from sourdough samples of Shandong province, China, lowered the UA index of mice serum. Furthermore, $L$. fermentum LFE0302 resulted in a significant reduction 

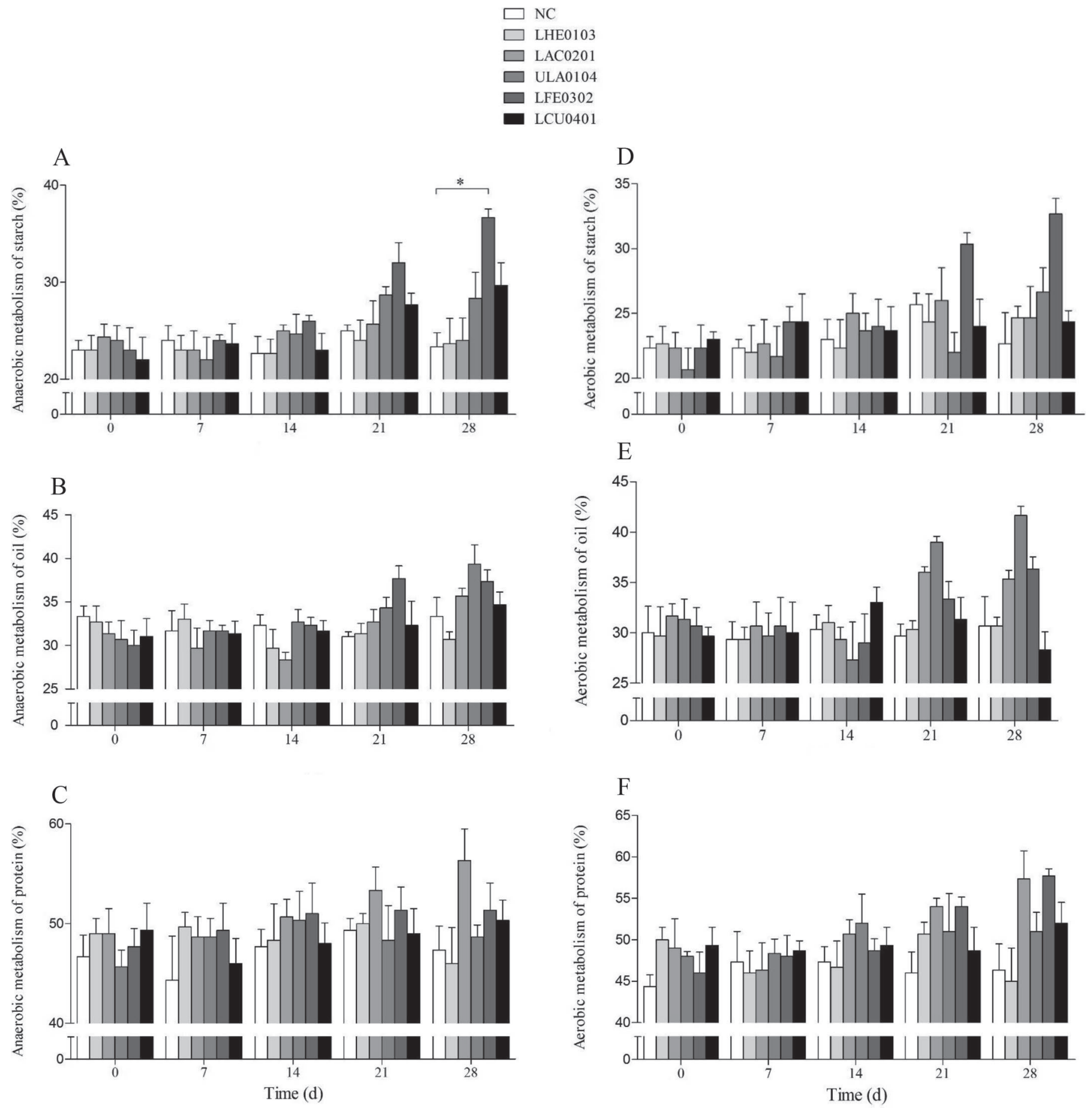

Figure 5. Metabolic capacity of fecal bacterial suspension in de Man, Rogosa, Sharpe broth (anaerobic) and nutrient broth (facultative anaerobic) at different times. Results represent the mean and SD rate of amylose metabolism (A and B), oil metabolism (C and D), and ovalbumin metabolism (E and $\mathrm{F}) .{ }^{*} P<0.05$ and ${ }^{*} * P<0.01$ versus the control group. $\mathrm{NC}=$ sterile physiological saline; LHE103 $=$ Lactobacillus helveticus LHE0103; LAC0201 = Lactobacillus acidophilus LAC0201; ULA0104 = Lactobacillus sp. ULA0104; LFE0302 = Lactobacillus fermentum LFE0302; LCU0401 = Lactobacillus curvatus LCU0401.

in opportunistic pathogens, Enterococcus and Enterobacter, and a significant increase in the counts of Lactobacillus. Moreover, we found a significant increase in starch digestion after 4 wk by anaerobic bacteria in the test group of L. fermentum LFE0302. Likewise, we noted a significant increase in $\alpha$-glucosidase activity in 

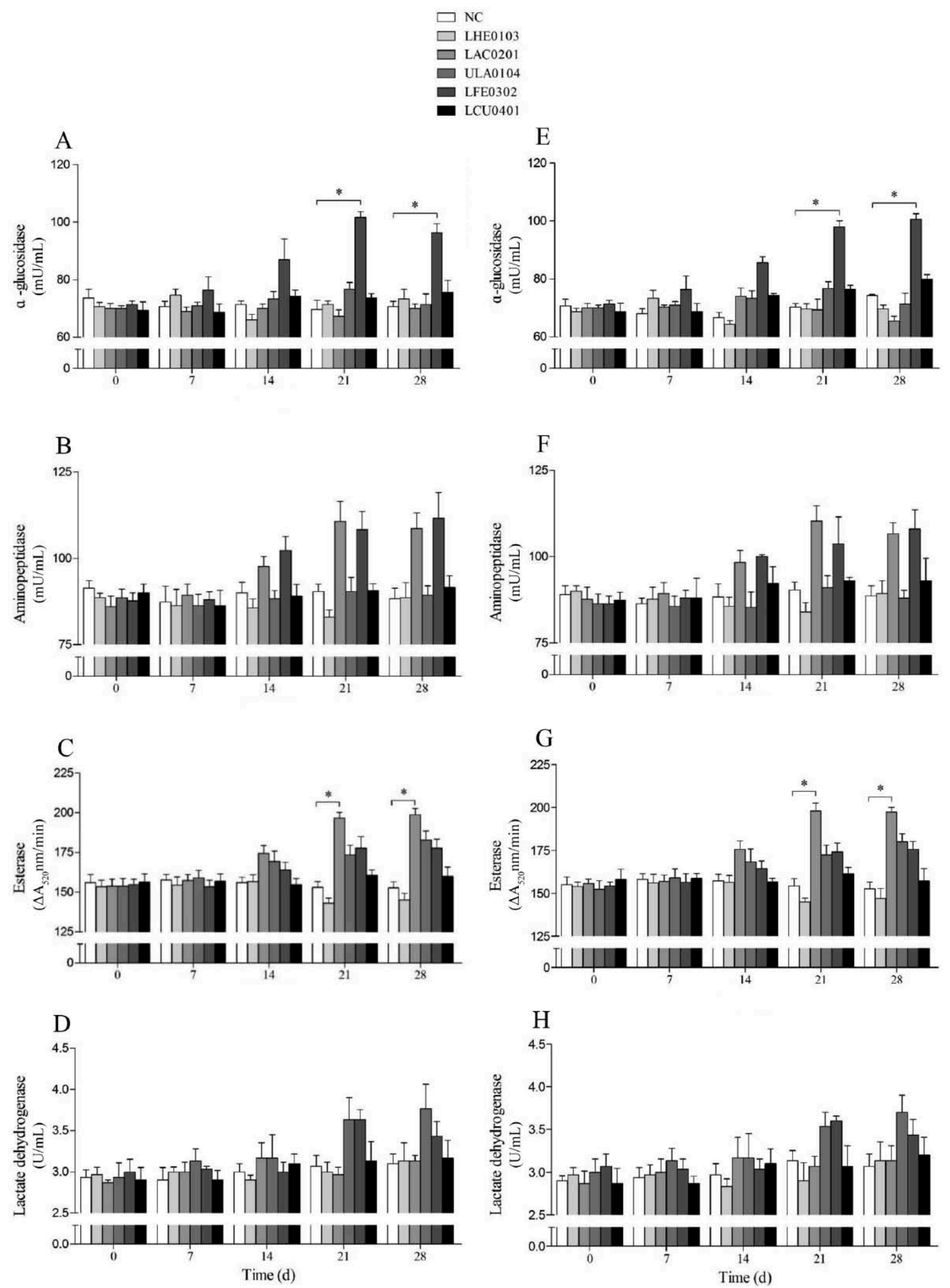

Figure 6. The activity of metabolism-related enzymes of gut flora at different time in the (a) cultured bacteria group and (b) fecal bacteria group. Results represent the mean and SD of $\alpha$-glucosidase activity (A), lactate dehydrogenase activity (B), esterase activity (C), aminopeptidase activity (D). ${ }^{*} P<0.05$ and ${ }^{* *} P<0.01$ versus the control group. $\mathrm{NC}=$ sterile physiological saline; LHE103 $=$ Lactobacillus helveticus LHE0103; LAC0201 = Lactobacillus acidophilus LAC0201; ULA0104 = Lactobacillus sp. ULA0104; LFE0302 = Lactobacillus fermentum LFE0302; LCU0401 = Lactobacillus curvatus LCU0401. 
the intestinal flora after administration of L. fermentum LFE0302 after 3 wk. Hence, our study suggested that L. fermentum LFE0302 from Chinese traditional sourdough was able to modify intestinal microbiota toward a positive flora balance, and influenced metabolism of sugar, oil, and protein through related bacterial enzyme activity.

\section{ACKNOWLEDGMENTS}

This project was sponsored by the National Natural Science Foundation of China (NSF31260363, 3100048, 31170091, 81160494), Chinese High-tech R\&D (863) program (2014AA022209), Ganpo Talent 555 Engineering Project of Jiangxi Province.

\section{REFERENCES}

Arroyo, R., V. Martín, A. Maldonado, E. Jiménez, L. Fernández, and J. M. Rodríguez. 2010. Treatment of infectious mastitis during lactation: Antibiotics versus oral administration of lactobacilli isolated from breast milk. Clin. Infect. Dis. 50:1551-1558.

ben Omar, N., and F. Ampe. 2000. Microbial community dynamics during production of the Mexican fermented maize dough pozol. Appl. Environ. Microbiol. 66:3664-3673.

Bessmeltseva, M., E. Viiard, J. Simm, T. Paalme, and I. Sarand. 2014. Evolution of bacterial consortia in spontaneously started rye sourdoughs during two months of daily propagation. PLoS ONE 9:e95449.

Breeuwer, P., J.-L. Drocourt, N. Bunschoten, M. H. Zwietering, F. M. Rombouts, and T. Abee. 1995. Characterization of uptake and hydrolysis of fluorescein diacetate and carboxyfluorescein diacetate by intracellular esterases in Saccharomyces cerevisiae, which result in accumulation of fluorescent product. Appl. Environ. Microbiol. 61:1614-1619

Chen, D., H. Zhang, Y. Gao, Z. Lu, Z. Yao, Y. Jiang, X. Lin, C. Wu, $\mathrm{X}$. Yang, and A. Tan. 2015. Cross-sectional and longitudinal associations between serum uric acid and metabolic syndrome: Results from Fangchenggang Area Male Health and Examination Survey in China. Clin. Chim. Acta 446:226-230.

Chen, T., S. Jiang, S. Xiong, M. Wang, D. Zhu, and H. Wei. 2012 Application of denaturing gradient gel electrophoresis to microbial diversity analysis in Chinese Douchi. J. Sci. Food Agric. 92:21712176.

De Vuyst, L., and P. Neysens. 2005. The sourdough microflora: Biodiversity and metabolic interactions. Trends Food Sci. Technol. $16: 43-56$.

Delzenne, N. M., A. M. Neyrinck, F. Bäckhed, and P. D. Cani. 2011. Targeting gut microbiota in obesity: effects of prebiotics and probiotics. Nat. Rev. Endocrinol. 7:639-646.

Drissi, F., D. Raoult, and V. Merhej. 2016. Metabolic role of lactobacilli in weight modification in humans and animals. Microb. Pathog. In press.

El Kaoutari, A., F. Armougom, J. I. Gordon, D. Raoult, and B. Henrissat. 2013. The abundance and variety of carbohydrate-active enzymes in the human gut microbiota. Nat. Rev. Microbiol. 11:497-504.

Gaur, R., T. Grover, R. Sharma, S. Kapoor, and S. K. Khare. 2010. Purification and characterization of a solvent stable aminopeptidase from Pseudomonas aeruginosa: Cloning and analysis of ami- nopeptidase gene conferring solvent stability. Process Biochem. 45:757-764.

Gobbetti, M. 1998. The sourdough microflora: Interactions of lactic acid bacteria and yeasts. Trends Food Sci. Technol. 9:267-274.

Hassanshahian, M., M. S. Zeynalipour, and F. H. Musa. 2014. Isolation and characterization of crude oil degrading bacteria from the Persian Gulf (Khorramshahr provenance). Mar. Pollut. Bull. 82:39-44.

Ishihara, H., H. Wang, L. R. Drewes, and C. B. Wollheim. 1999. Overexpression of monocarboxylate transporter and lactate dehydrogenase alters insulin secretory responses to pyruvate and lactate in $\beta$ cells. J. Clin. Invest. 104:1621-1629.

Koppe, L., D. Mafra, and D. Fouque. 2015. Probiotics and chronic kidney disease. Kidney Int. 88:958-966.

Li, M., D. Yang, L. Mei, L. Yuan, A. Xie, and J. Yuan. 2014. Screening and characterization of purine nucleoside degrading lactic acid bacteria isolated from Chinese sauerkraut and evaluation of the serum uric acid lowering effect in hyperuricemic rats. PLoS ONE 9:e105577

Liu, T., Y. Li, J. Chen, F. A. Sadiq, G. Zhang, Y. Li, and G. He. 2016. Prevalence and diversity of lactic acid bacteria in Chinese traditional sourdough revealed by culture dependent and pyrosequencing approaches. LWT Food Sci. Technol. 68:91-97.

Mañé, J., V. Lorén, E. Pedrosa, I. Ojanguren, J. Xaus, E. Cabré, E. Domenech, and M. A. Gassull. 2009. Lactobacillus fermentum CECT 5716 prevents and reverts intestinal damage on TNBS-induced colitis in mice. Inflamm. Bowel Dis. 15:1155-1163.

Park, J.-W., and D. E. Crowley. 2005. Normalization of soil DNA extraction for accurate quantification of target genes by real-time PCR and DGGE. Biotechniques 38:579-586.

Ramezani, A., and D. S. Raj. 2014. The gut microbiome, kidney disease, and targeted interventions. J. Am. Soc. Nephrol. 25:657-670.

Sayin, S. I., A. Wahlström, J. Felin, S. Jäntti, H.-U. Marschall, K Bamberg, B. Angelin, T. Hyötyläinen, M. Orešič, and F. Bäckhed. 2013. Gut microbiota regulates bile acid metabolism by reducing the levels of tauro-beta-muricholic acid, a naturally occurring FXR antagonist. Cell Metab. 17:225-235.

Scalabrini, P., M. Rossi, P. Spettoli, and D. Matteuzzi. 1998. Characterization of Bifidobacterium strains for use in soymilk fermentation. Int. J. Food Microbiol. 39:213-219.

Schnabl, B., and D. A. Brenner. 2014. Interactions between the intestinal microbiome and liver diseases. Gastroenterology 146:15131524

Simões, C. D., J. Maukonen, J. Kaprio, A. Rissanen, K. H. Pietiläinen, and M. Saarela. 2013. Habitual dietary intake is associated with stool microbiota composition in monozygotic twins. J. Nutr. 143:417-423.

Tamime, A. Y. 2002. Fermented milks: A historical food with modern applications-A review. Eur. J. Clin. Nutr. 56:S2-S15.

Tremaroli, V., and F. Bäckhed. 2012. Functional interactions between the gut microbiota and host metabolism. Nature 489:242-249.

Tsangalis, D., J. Ashton, A. McGill, and N. Shah. 2002. Enzymic transformation of isoflavone phytoestrogens in soymilk by B-glucosidase-producing Bifidobacteria. J. Food Sci. 67:3104-3113.

Vilaplana, F., J. Hasjim, and R. G. Gilbert. 2012. Amylose content in starches: Toward optimal definition and validating experimental methods. Carbohydr. Polym. 88:103-111.

Wu, Y., W. B. Liu, H. Y. Li, W. N. Xu, J. X. He, X. F. Li, and G. Z. Jiang. 2013. Effects of dietary supplementation of fructooligosaccharide on growth performance, body composition, intestinal enzymes activities and histology of blunt snout bream (Megalobrama amblycephala) fingerlings. Aquacult. Nutr. 19:886-894.

Xie, J.-H., S.-T. Fan, S.-P. Nie, Q. Yu, T. Xiong, D. Gong, and M.Y. Xie. 2016. Lactobacillus plantarum NCU116 attenuates cyclophosphamide-induced intestinal mucosal injury, metabolism and intestinal microbiota disorders in mice. Food Funct. 7:1584-1592. 